\title{
CosMuseum Project: Memories and Souvenirs from planet Earth
}

\author{
${ }^{1}$ Charles Darwin University, Australia \\ ${ }^{2}$ Charles Darwin University, Australia \\ ${ }^{3}$ Museum and Art Gallery of the Northern Territory, Australia \\ 4National Museum of Contemporary Art, Greece
}

Ioannis Michaloudis*1, Ian Hance ${ }^{2}$, Christine Tarbett-Buckley ${ }^{3}$ and Katerina Koskina ${ }^{4}$

Submission: July 30, 2018; Published: September 12, 2018

*Corresponding author: Ioannis Michaloudis, College of Indigenous Futures, Arts and Society, Charles Darwin University, Australia, Email:michalous@gmail.com

\begin{abstract}
The etymological origin of the word museum is muse. If the muse of our space era is the Cosmos itself, then a CosMuseum is our proposition for a nomad museum in space, carrying artworks-memories from Earth's civilization. Remembering that every additional gram of cargo in space expeditions is extremely expensive, the lighter the cargo is, the more economical the expedition will be.

Conclusion: we cannot carry Pyramids and Parthenons to the CosMuseum. Thus, this paper is proposing Michaloudis cultural cargos for this imaginary museum in space; sculptures made of the lightest solid on planet Earth together with a combination of digital images from Hence's artworks. The author's first immaterial artworks are directly influenced by Cycladic art. The co-author's artworks are based on the traditional medium of oil on canvas, which are based on earthly constructions of termite mounds. In this paper we'll present some of their artworks and posit them as potential precursors for a cultural cargo from our (h)Earth.
\end{abstract}

Keywords: Museum, Catastrophe, Silica aerogel, Periphery, Souvenir, Memory, Canvas, Termite mounds

\section{Introduction}

Dr. Ioannis Michaloudis is a forerunner in research regarding the use of materials that bridge art and the new sciences of space. The primary material currently dominating his research has been developed by NASA, the nanomaterial silica aerogel into which he sculpts his aer( )sculptures. Ian Hance is a PhD student at Charles Darwin University under the supervision of the author. His works consist of oil paintings on canvas based upon the subject of termite mounds, native to the Northern Territory, which unknown tourists adorn with found objects in various arrangements. The third coauthor, Christine Tarbett-Buckley is the Head of Collections at the Museum and Art Gallery of the Northern Territory and a Research Fellow at Charles Darwin University. She has a background in archaeology, art and law and museology with research interests in the evolving concept of the museum and the sustainability of museum collections into the future. Dr. Katerina Koskina is an Art Historian-Museologist and in nowdays the Director of the National Museum of Contemporary Art in Athens, Greece. She was the curator of Michaloudis' solo exhibition 11 aer( )sculptures in the Cycladic Museum of Athens back in 2006. This paper interrogates the practices/research of the two artists with the hypothesis that it will be necessary at some time, in the not too distant future, to situate a museum in space both as a repository of both original artworks and as simulacra for works too large or weighty to be installed. We maintain that the physical constraints will not allow for the installation of art pieces or architecture that are typical to the current museum arrangement. It is therefore our contention that replicas and original art need to be rendered in weightless materials, digital records, holograms, light projections and other media yet to be discovered. The last sections discusses the natures and contexts of a CosMuseum as seen by curators Christine Tarbett-Buckley and Katerina Koskina. Thus this paper is a discussion of themes and contexts from two distinct perspectives-that of practising artists and of museum professionals.

Michaloudis is a sculptor combining art with technology by using the space era nanomaterial silica aerogel. It constitutes of $99,9 \%$ air and $0,1 \%$ glass and has been extensively used by NASA for the collection of stardust. When he was first introduced to the material he was permitted its use only for the creation of small size artworks. His concept of creating moulds of Cycladic figurines was a result of the convention of their size. He suggests that these primitive figurines function as a symbol 
representing the self, one that is widely recognizable by the public as such. This recognition enabled him to promote his technique through utilising symbols familiar to the observer to create an overarching theme. He called his work aer()sculpture as the only source is light in the absence of material. He chose silica aerogel as a contrasting material with marble to create a dialogue between the lightness of the aer()sculptures and the weightiness of the marble figurines.

The incentive force of sculptural metamorphosis of the Cycladic form may have plotted the chronological course from the historically-loaded material of marble to the nowadays space technology nanomaterial, suggesting a parallel journey that started from the authentic form and finished as a "fake" copy. To the artist, this journey could be summarized through the creation of a pun on the Greek word plastos that has the dual meaning of 'sculpted/modeled' and 'fake', with particular reference to tourist souvenirs. The discussion of visual records in digital photography speaks also about disappearance, namely the original material that is left behind or perceiving the original in an altered form, from a peripheral viewpoint. Both artists and the one of the curators are situated in a unique positioning of periphery being at the last frontier of Australia, Darwin in the Northern Territory. Within this context, the periphery functions as a stimulus to both produce art and to secure its preservation. The dialectics of materiality/nonmateriality of original to copy are examined through the workings of ambiguous space, colour and form in the discussion of Michaloudis's sculptures and Hance's oil paintings on canvas.

The materials discussed include the primary material of silica aerogel in Michaloudis's aer() sculptures and Hance's oils on canvas and the digital images he captures his subject matter with. Then follows a discussion of the formal, nonformal aspects of the imagery based upon Cycladic figurines in their reference to Neolithic fertility idols and how both of these references find their poetic connections as memories and souvenirs. These memories and souvenirs from planet Earth are to be placed in a hypothetical museum of the future named here as CosMuseum.

\section{Views from the Periphery}

The view from space of Australia on the television screen is so familiar and central whether that is on the weather channel or the news channels yet its cultural positioning in the western perspective has always been considered marginalised, (Figure 1). Historically it was one of the last continents to be mapped by Europeans. To Australians, the last mass of Oceania was always their centre and any effect of the perceived periphery on their culture will not be discussed here. However, the significance of memory in the oral tradition of Australia's Indigenous peoples will form part of the argument for inclusion of souvenirs and memories in the museum, to offset the sole reliance on digital data. Darwin's remoteness in this largest of all islands stands as a personification for the remoteness of space or planet Earth's remoteness within our solar system and beyond. The experience of the materiality of visual cultures from the "centre", that is the rest of the world, has always been Eurocentric.
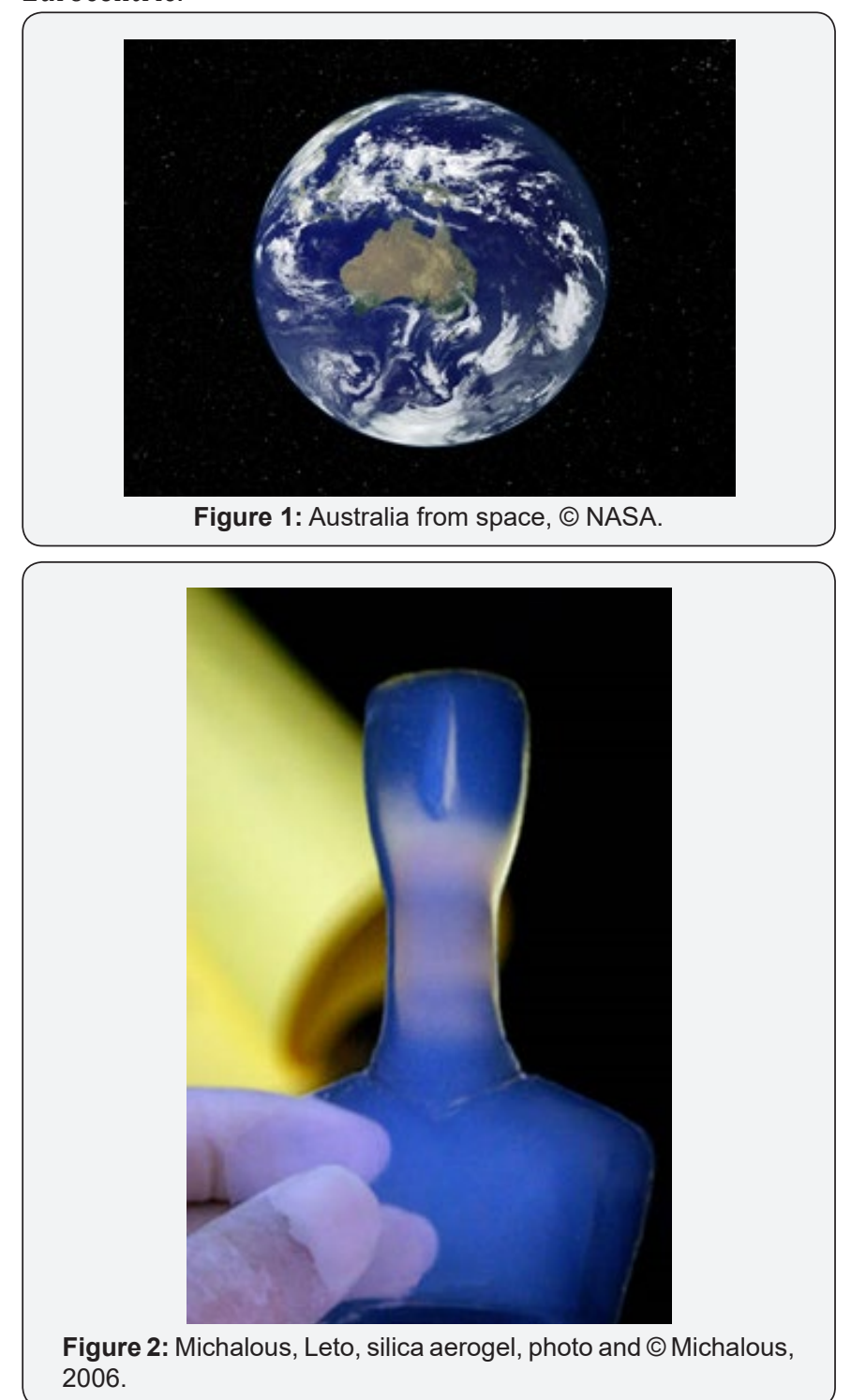

The Australian viewer's experience of international artworks has required leaving this island in order to see such works physically. For the rest of the time this experience has been substituted with the experience of the photographic reproduction or online digital records [1]. It can be argued that an artist in this context of the periphery is in an excellent position to reflect on what are the possibilities beyond this horizon; as being located on the periphery can provide a clearer picture of the whole than can be experienced within the confusion of the centre. The periphery can be a stimulus to produce art. The periphery of Earth in the edge of space is addressed within Michaloudis's works while the subject matter of termite mounds for Hance's paintings are peripherally located on remote areas of the highways of the tropical north of Australia, (Figure 2\&3). Hance's costuming of these mounds is 
a humorous expression of tourist's desire to see the nakedness of these anthropomorphized mounds covered with clothing and other materials. The concepts of distance and tourism are discussed later in nostalgia, memories and souvenirs. Art itself can be considered as a peripheral activity in that it has a secondary or removed aspect from the primary source of observation.

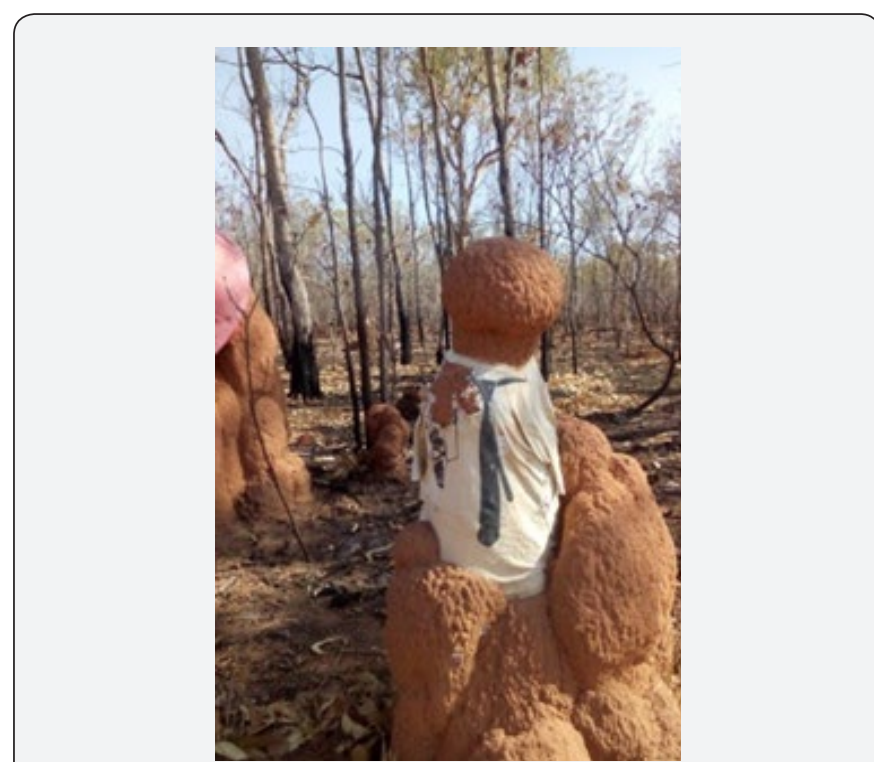

Figure 3: Costumed Termite Mound, near Katherine, Northern Territory, Australia, photo and (C) Ian Hance, 2016.

Another view of space that is clearer from the periphery is the view of the night sky/space itself. Unlike most metropolises, Darwin has relatively little night light pollution and even a short drive out of Darwin produces excellent views of our solar system and the Milky Way. The primordial contact that humanity has with the cosmos here is visually much more pronounced. The dialectics of natural light and artificial are brought into sharp contrast by light pollution. The view of space from major centres of the world is compromised by this pollution. For this reason it is unsurprising that the telescopes on Earth are situated in remote locations or placed in orbit around the earth, again at the periphery.

\section{Catastrophe: breaking materiality and remoulding immateriality}

The initial colonialization of Australia can be considered as a catastrophe for the culture of Indigenous Australians. There have always been catastrophes for other cultures historically with the disappearance civilizations and their artefacts, and possibly with the merging of new cultures. The possibility of cultural disappearance of any of the world's societies is just as concerning in the twenty-first century as at any time in the past. It is with this threat in mind that the author's proposal of a nomad museum containing artworksmemories is a more urgent consideration than an "ark" of artefacts. What these artworksmemories will be made up of -or rather their imagined possibilities- are discussed in the following.

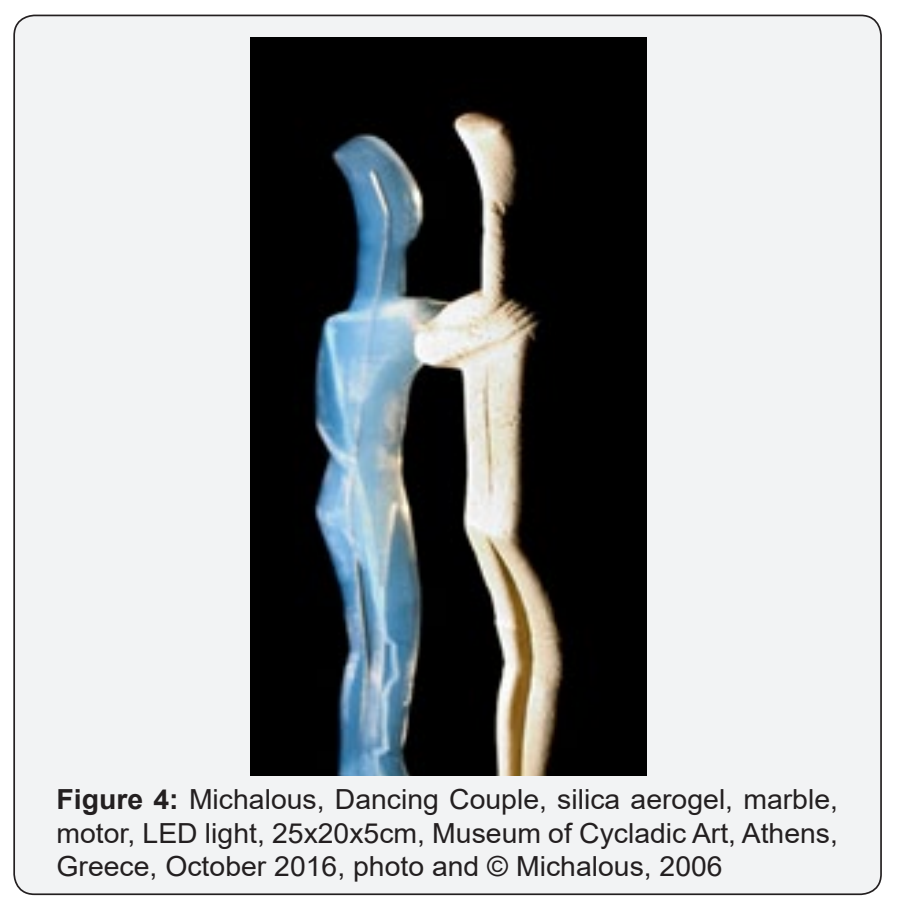

The word terroir (from the French word for "earth") evokes memories of flavours/scent of the terrain. All the earthly ecosystem factors that make up the characteristic of a product, is terroir. In the author's case, the cloudlike silica aerogel carries the scent of earth's sky as seen in Figure 2. In the co-author's case, the product is oil paintings of termite constructions (mounds) made of earth in the Northern Territory (Figures $3 \& 4$ ). We see these residues or flavours as a kind of terroir, a kind of subtle overtone or undertone rather like the complex flavours in wine, forming a subtle metaphor for the "associative radiances" or a memory of the earth itself. The catastrophic breaking and scattering mentioned later as part of these nostalgic memories speaks about the processes of creativity itself: the other side of the coin of creating is destroying or "breaking the mould". In Michaloudis's practice, the very solid steel mould has to be "broken" to reveal the magical nonmateriality of the silica aerogel sculpture. In Hance's works the visual breaking up of the space and formal 3D properties of the termite mound /mould constructions into visual metaphors, coupled with their abstraction into bidimentional painting is the complement to the formative properties of Michaloudis's sculpture. The discussion of the dialectics of materiality/ nonmateriality through these properties follows: in the author's case, the effects of light in a space/atmospheric medium of silica aerogel and in the co-author's the earth bound medium of oil colour in its application to this abstract space and form will be discussed below.

\section{Dialectics of materiality}

Silica aerogel consists of 1 per cent glass and 99 per cent air, making it the lightest solid material on Earth [2]. The scattering of light as seen in the Rayleigh effect is part of the material properties of silica aerogel in which the source of light 
changes the colour depending whether it is seen against dark or light. In Michaloudis's Leto (Figure 2) the ethereal blue quality and its translucency contrasts against the suggested weight of the Cycladic form when it is set against a black background. The opposite complementary color that makes up the Rayleigh scattering -gold yellow- is seen as a formal edge reflecting against the formless black of space. The edge suggests skin or surface; however, the skin or surface of the works is almost invisible whilst the interior space of the works as coloured volume or mass is poetically amplified. Similarly, the analogy between the skin of the anthill construction with its clothing and the skin of paint both conceal and reveal space as a volume within Hance's paintings (Figures 5-7).

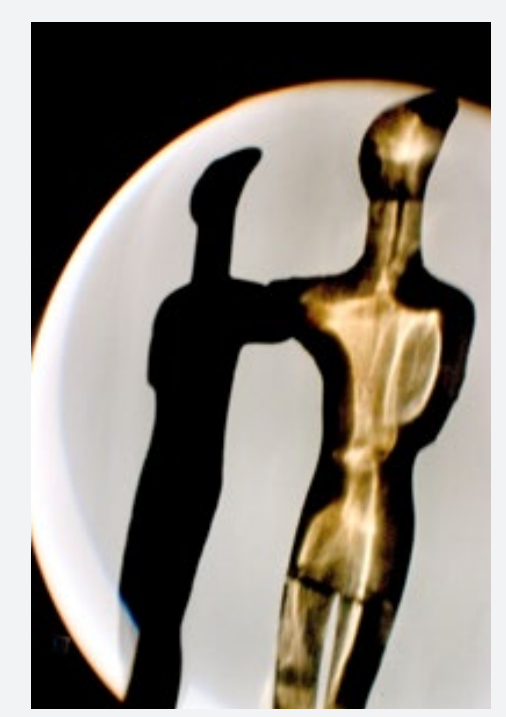

Figure 5: Michalous, Dancing Couple, projected shadow on translucent screen, in situ installation, $250 \mathrm{~cm} \times 250 \mathrm{~cm} \times 250 \mathrm{~cm}$, Cycladic Museum of Athens, photo and @ Michalous, 2006.

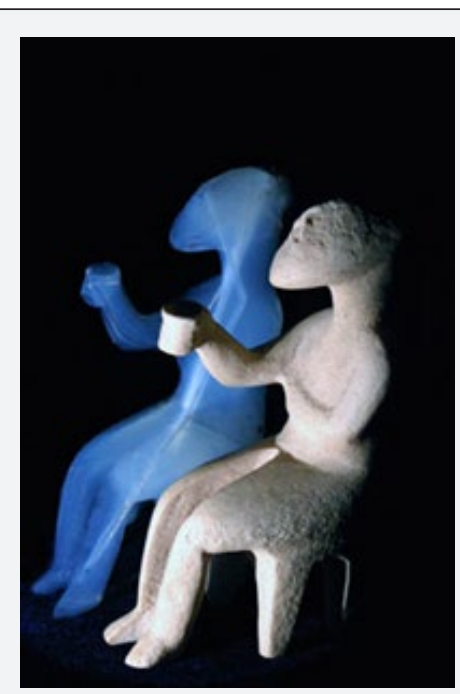

Figure 6: The cup-bearer, marble, Cycladic, Early Cycladic II period - Syros phase, 2800-2300 BC, Height: $15.2 \mathrm{~cm}$, unknown provenance, Museum of Cycladic Art, Athens, Greece. Michaloudis' silica aerogel sculpture is weighting only 20 grams, the marble one 350 grams, photo and ๑ Michalous, 2006

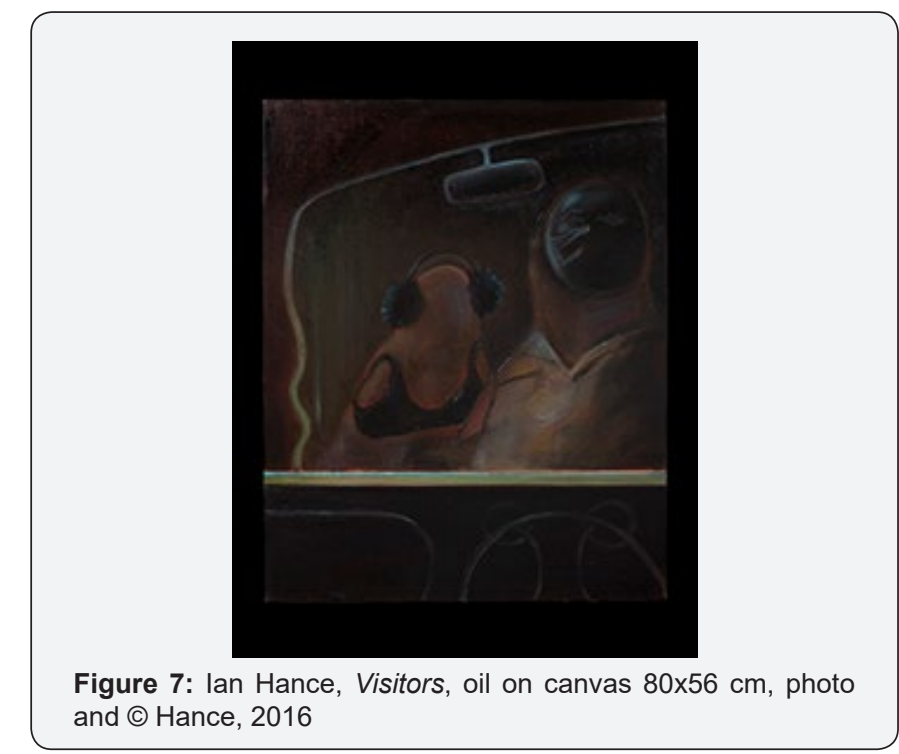

Thus, Michaloudis's works are ambiguously both formal and formless, similar to vapour or smoke. When these works are set against the black void, their conflicting qualities speak of the spiritual and the dialectic of material/mystical. These properties stress the function and the binary opposites of colour as complementary and function as an expression of the spiritual, abstract and perhaps mysteries of the cosmos via their ambiguities of space and hue. In Michaloudis' works, many of the sculptures and artworks represent symbolically an anthropomorphised female figure in some of the Neolithic Cycladic figurines. This symbol can also be located in Hance works through the termite mound functioning as a "Mother" form. Within this reference we can locate other fertility idols such as the Venus of Willandorf. Michaloudis notes that his Cycladic figurines similarly reference a symbol for the self which is widely recognisable and resonate with the public. That there are references to James Lovelock's hypothesis of Gaia, or, put in a more poetic way, Mother Earth, in addition to this original symbol of the fertility goddess. The Mother Earth reference adds poignancy to the sculpted and dematerialised images that could be placed in the CosMuseum. In Hance's case the representation of these anthropomorphised figures of the termite mounds is the counterpoint to the ethereal qualities of the silica aerogel sculptures mentioned previously.

In Michaloudis' work the cup-bearer, (Figure 6) the dialectics of the weight of solid marble and the ethereal light qualities of the silica aerogel provoke feelings of ambiguity in its relationship to the density of the souvenir as an object embodying a sense of memory (and terroir). Both objects are seen in Figure 3 set against void or black space, which itself holds both formal and informal connotations in its reference to the concepts of the formlessness and its mutability [3]. In Michaloudis' artworks the figures/constructions are nearly always seen against these black rectangles ovals and squares which actively reference either the cosmos in a formal 
way or the void in its connotations of disappearance. Form functioning against the void and the suggested "memory" of an original form plays with the ideas of plastos in this work"fake" as in a souvenir taken from the original archaic marble Cycladic sculptures. These are copied into tourist market copies as souvenirs for sale. From these copies Michaloudis makes a mould (memory) in which the silica aerogel is cast. The point being here that material souvenirs are very different from memories, and the authors hypothesis asks whether the artists operating on the periphery are in a more advantageous position to consider the "collection" of the whole; say of digital memories and works of art in space age materials, not just souvenirs in their materiality Two works reference the duality of the past in the present and extend possibilities for their entire representation within a future museum. The Dancing Couple in Figure 4 and Figure 5, through its use of space age material recreates an original form as a duplicate of a missing/lost "idol" which produces a shadowed reflection as an immaterial duplicate. These artwork regenerate the past through their inclusion of lost elements of cultural icons. Their resemblances in the present converge as an idealised representation for the future.

\section{Memory in Future Time}

The materiality of memory in Michaloudis' works are discussed in the following catalogue's text by the curator Katerina Koskina for his solo exhibition 11 aer( )sculptures in the Cycladic Museum of Athens, back in October 2006. "Ioannis Michalou(di)s is one of those contemporary artists who though espousing international visual inquiry and language, and indeed is involved with their most recent experimental and scientific applications, remains at the level of idea and of form a supporter of local culture. Thus, from his interdisciplinary experience and training in both art and science, works have emerged that literally hover between the past and the future. This is due in large part to the material to which he was first exposed in a research at MIT and immediately began using silica aerogel., But Michalou(di)s, as he prefers to sign his surname, by contracting it, as he does also with the title of his recent works - voluntarily trapped in a game of knowledge and chance, of etymology and joke, was fascinated by this particular material, which looks like solidified air and is widely used by NASA because of its insulating qualities. Silica aerogel, although ubiquitous in space and high technology, is an unknown material and a scientific paradox for artistic creation, despite its truly magical image and texture, which allows it to "transform": the painted skies of the Venetian School into virtual reality. And yet its basic constituent, silica, for all its fragility, is a material of high durability to time, a material with continuity and memory. Perhaps this particular characteristic of it makes it most suitable for serving a diachronic value such as art.

In an age when everything aims at dematerialisation, this material composed of $99 \%$ air and $1 \%$ glass follows the opposite course. In essence it "materialises" "nothing" and it owes its plasticity not to its principal ingredient, air, but to that minimal percentage of glass, which gives it "body". That is why Michalou(di)s has called his works aer( )sculptures, revealing both their constitution and the sidereal origin of his material. A material that exists pre-eternally in the universe in the form of particles, but whose present form is so recent that it is considered a material of the future.

However, what is more interesting for the viewer of the works is not the composition or the provenance of the material, for all the admittedly alluring image it offers, but the way in which the artist incorporates it in the creative process. Michalou(di)s uses the astral material to represent Cycladic figurines, that is works of the $3^{\text {rd }}$ millennium B.C. This is not the first time that he feels that the ancient form demands from him a metamorphosis. The archetypal form of the Cycladic figurines, which is the cultural nucleus not just of Greece but if the whole of the West, appears because of its abstraction eminently timely and suitable for "habitation" by a supermodern material. Michalou(di)s apparently conceived this message of the timelessness and modelling of form, which inhabits the collective subconscious, when he decided to predict the future image of the figurines by "embracing" them with the nostalgia distinctive only of a Greek who has lived abroad for many years."

\section{Chaos as background}

In both the black ground of the sculptures and paintings, (black being an amalgamation of all colours of the spectrum in an additive way) Michaloudis' sculptures also experiment with the disappearance of colour and light. In Michaloudis' sculptures the disappearance or flux perhaps between the polarities of light contained in the aerogel produces the complementary colours of blue and a golden orange (depending on which view is taken of the work). This mutability or shifting of view is an expression of the spiritual values in our contemplation of the cosmos, or at least the importance of a shifting perspective underpinned by the dialectics of materiality/non-materiality. The description of Michaloudis' aer()sculptures as being the only source of light in the absence of material or a non-materiality of the aerogel forms a poetic expression of both the spiritual form or memory. The painted black backgrounds of Hance's work similarly reference both void and formal space at the same time. They also reference the in-between space of the canvas itself covered by pigment, the sensed space of advancing forms surfacing in the picture plane. Rather than receding back into the picture plane as in Renaissance perspective, the volumes established sit forward in ambiguous space, (Figure 7). Glossy transparent backs and solid black pigments combined with their relative "silvers" explore this in-between space. Other artists such as Gerhardt Richter and Rembrandt have used the ambiguities of black. Rembrandt's tensions of warm and cool blacks similarly give life and articulation to an otherwise void of black. Pierre Soulages 
similarly used impasto glossy blacks against flat blacks to explore formal and spatial properties. The void also speaks about disappearance and if we accept Baudrillard's concepts of reality in our age (the Anthropocene) as disappearing behind the black screen of the Internet and digital media, there is poignancy inherent in the black screen or black rectangle of painting in the sense of loss or absence [4]. Black also speaks about the invisible and as such invokes the non- material or spiritual. On the other hand, a texture and impasto surface in black paint draw attention back to the surface and thus speaks about the weight or gravity of the artwork. The black circle in Michaloudis's gold Cycladic figurines holds expression of the chaos of the void whilst simultaneously creating a tangible space established by the perspectival positioning of the two Cycladic figures (Figure 8).

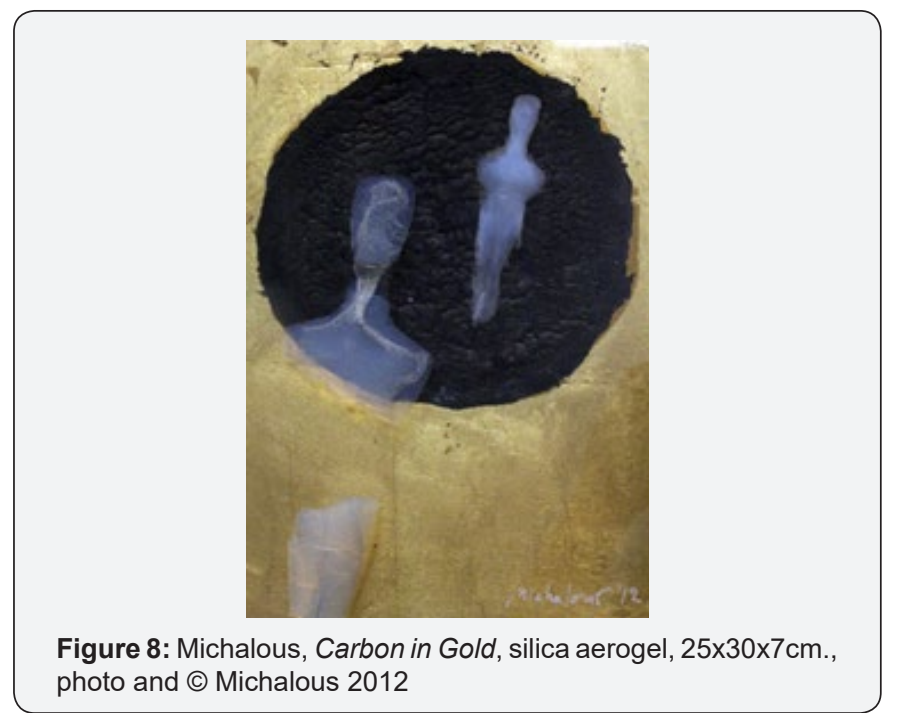

The weighty solid panel made of scorched wood in Figure 8 is covered in gold leaf accentuates the weightlessness and suggested movement of the silica aerogel figures. Gold in itself sits ambiguously between form and light in its reflective properties and its physical metallic property. Conceptually it references the spiritual in its associations with cultural symbolism of the divine. Not so in Hance's work Night Piece (Figure 9), in which materiality references the purely secular in its references of the earthly grotesque soil presented a basic human female form. The dressed up figure is set within the space of the periphery of a township against a warm black that functions as both atmosphere and solid humidity. This black is suggested by a solid impasto paint surface and includes visible fluid runs of paint. Again black is used in its ambiguities of weight and weightlessness. The singular figure evokes a feeling of solitude and isolation that also expresses the periphery. A connection to ancient images such as the Wandjina (Figure 10), which is executed in a similar medium, that of earth/red ochre, reinforces concepts of earth bound materials. However, these Wandjina are representations of spirit beings grounded in earth's palette; a counterpoint to the spiritual blue of Michaloudis's Cycladic figurines. The Wandjina figures are earth bound in more ways than one; being painted on a rock shelter -like the pyramids and the Parthenon- they can never be transported to a space museum.

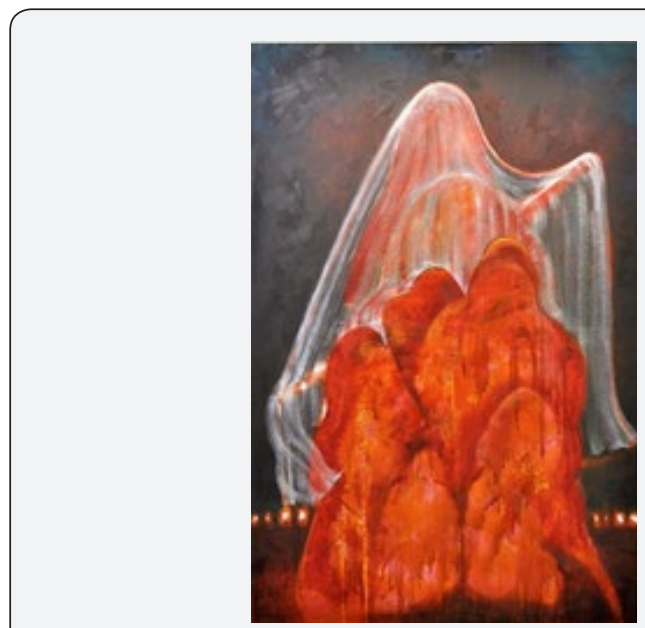

Figure 9: lan Hance, Night Piece, oil on canvas $180 \times 130 \mathrm{~cm}$, photo and $\odot$ Hance 2016.

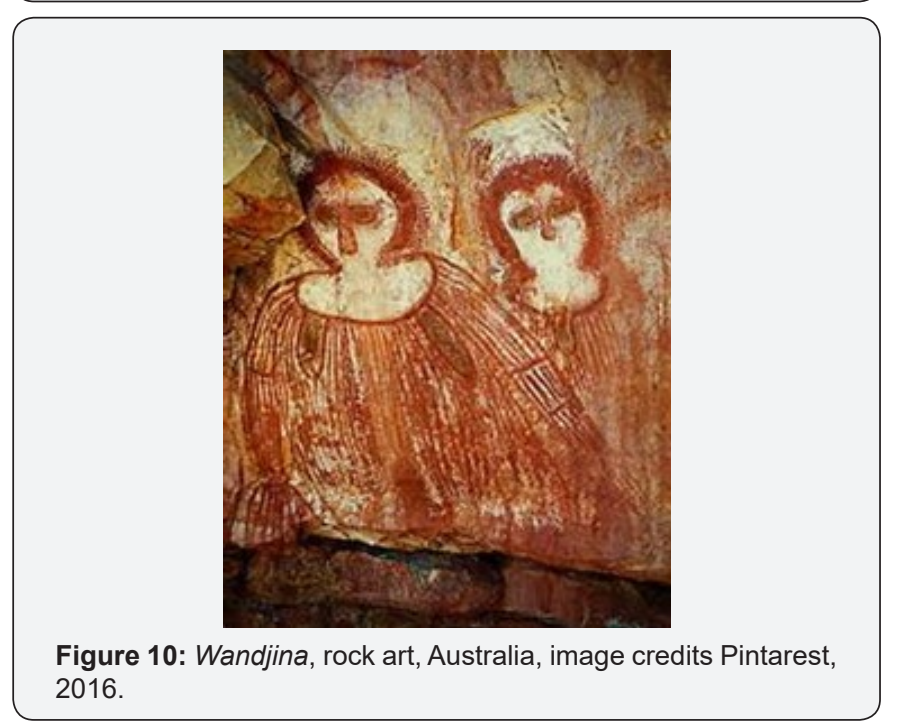

Further to the dialectics of materiality/non materiality, the idea of translating the digital images of the works into light images for a repository, a CosMuseum in space is proposed in order to hold memories of earthly constructions as art. In this process of the copy of a copy-or simulacra-the memories of earth and paintings produce nostalgia and an ironic reflection of what is left behind. Analogous are the processes of the mounds themselves as aspiring to become space themselves, both internally and externally. The reproduction of original works based upon the digital recording (a copy) are then copied by a digital photograph (a copy) to be reinvented into the digital trace that finally appears on the screen in the form of RGB light that constitutes pure digital data. Through these methods we enter the arena of the aesthetics of disappearance, which reside in memory, nostalgia and our imaginations. 
Novalis's quote "philosophy is really a nostalgic desire to be at home" points to a fundamental truth about memory being bound up in nostalgia that is also beautifully alluded to in another quote from Proust's Swann's Way; “When nothing else subsists from the past, after the people are dead, after the things are broken and scattered... the smell and taste of things remain poised a long time, like souls...bearing resiliently tiny and almost impalpable drops of their essence, the immense edifice of memory". Thus the question arises; how can a museum in space help to create a sense of belonging contained within our memories? As with any movement of humanity into newly colonised land (or space) there is traumatic disjuncture with a new environment. Historically when any civilisation repositions in new territory, it carries a raft of problems, not least is the equating of this new territory as home. As Stephen Muecke puts it, "...existence of course is precarious, but never more so than when it is conceived as being without attachment or belonging" [5].

The current world crises in refugee movement and migration have brought this problem into sharp focus. The authors propose that similar to the movement of migration people need to carry their culture with them and therefore cultural cargoes must be made manageable in order for space needs to be addressed. Thus another question arises; is it through dualities and ambiguities that some of these issues can be viewed via shifting perspectives? As discussed above, Michaloudis's and Hance's research and resultant works contain dualities of meanings and overlays of cultural signifiers. Both artists use the ideas of tourist souvenirs kept and things or traces left behind as their primary subject matter. These processes point to new ways of registering memory as traces, taste or scents and in non-written way as in the initial description of Terroir and nostalgia.

The mention of the non-written invokes association to memories, which are embodied in the oral traditions of Indigenous peoples. Indigenous culture binds the visual image to the important stories and natural sciences. The absence of the written word within these cultures allow a special profundity that is never forgotten simply because it must always be retained as memory. The image of the rock painting of Wandjina in the Kimberley is an excellent example of knowledge and cultural memory bound into a single image the image itself being the primary language, which contains the spiritual values of the Dreamtime interwoven with the physical aspect of the earth-bound timing of the arrival of the wet season [6]. The increase in humidity make its earth colours much more vivid at this period making the image "live". These images are "sets of symbols used to communicate meanings developed into a symbolic universe, in which art, language, myth and religion (are) were interwoven ..." [6]. The implication is that the more we rely solely on recorded data, the more our memories atrophy. It is hoped that any museum of the future could include similar artistic memories as well as other records/ artefacts of natural history, science and cultural cargoes from earth.

\section{The Museum of the Future}

Is it perhaps then that through the eyes of artists who proposes the selection of what constitutes the museum of the future in its relation to the cultural memories of earth are to be addressed. In the past, such artists have considered a museum of the future as André Malreaux in 1967, who proposed in his "museum without walls" that photographic records of all important cultural artefacts be placed in a space as an economic and weightless record [7]. Similarly, it is proposed that a museum of the future would utilize new processes that apply or have been developed out of space age technologies that are also weightless and economic in size. An excellent example of an artist creating work from new material is embodied Michaloudis's sculptures made from the space material silica aerogel, reiterate that the artist's muse is the cosmos itself, coupled with the space technology that produced the silica aerogel [8]. Souvenirs and "souveniring" has always been the tangible evidence of tourism and the leaving behind of evidence or tourist memento states that "I was ( $t$ )here". The other notion that seems to drive such activities is the need to turn the "nowhere" of a remote place or space into "somewhere" [9].

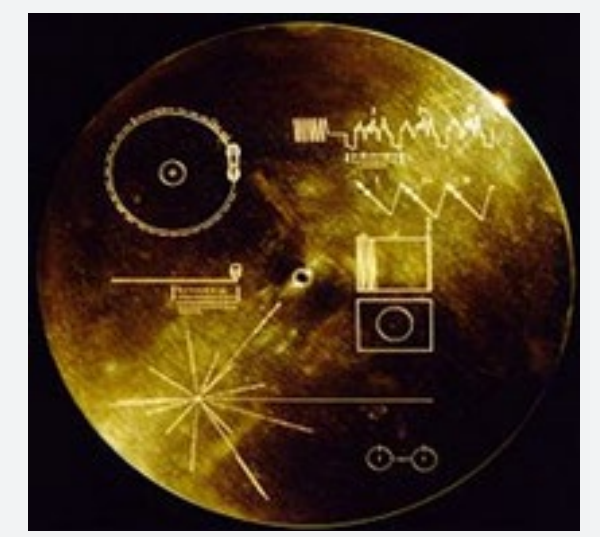

Figure 11: Cover for the golden record in Voyager probe, () NASA, 1977.

The golden disc sent out into the cosmos on Voyager in 1977 of course sends out a different message that of we are /were here (Figure 11). The "were here" holds a particular poignancy of the nostalgic. The point being here that material souvenirs are very different from memories, and the author's hypothesis asks whether the artists working in the peripheral are in a suitable position to think about a "collection" of the whole; say of digital memories and works of art in space age materials, not only souvenirs in their materiality (Figure 12). So, it is in the digital copy of digital copy of an analogue copy (or material copy) together with three -dimensional works are made from aerogel and/or other media creates the constraints for a new visual environment. Weightless media is in itself a type of memory or souvenir that we propose to be a light and colour soaked "apparition" constituting the artwork left behind or 
disappearing from Earth. The poetic interpretations of space fused into the working of materiality as a concept within the various mediums discussed here in the works of Michaloudis and Hance point to a new way of representing works of art as memory, and a different perspective on the possibilities of storing cultural cargoes.

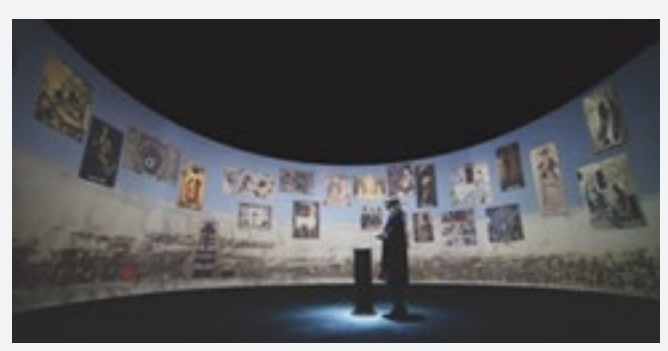

Figure 12: Virtual display of Mogao grottos at Dunhuang caves, Gobi Desert, China, staged in a 360-degree 3D interactive enclosure in Kenderdine, S. 2016, pp. 204 @ Applied Laboratory for Interactive Visualisation and Embodiment (AliVE), CityU, Hong Kong.

These possibilities of storage extend outside their function as merely souvenirs from Earth to suggest their ability to also manifest as profound memories. As these materials and copies are the lightest and most spatially economic mediums known to date, they are eminently suitable to be housed in a CosMuseum the museum of the future. CosMuseum is imagined as a virtual and universal museum. Its collection is created as a data bank sculpted from an aggregate of museum digital data, developed in a unified structure by the global museum community and enabled through virtual transmission into the cosmos. CosMuseum opens up the possibility of a narrative environment that is representative of our collective humanity, unbounded by temporality, and made accessible to an audience both known and unknown. It is destined to provide a space symbolic of our times, one that acknowledges the incognisant of the present. Simultaneously the museum posits a vision towards a timeless future, in which visitors in space may process visual and sensory cues in ways we cannot control, imagine or predict. CosMuseum is envisaged to contain the memory of our present, almost as simulacra of Earth's cultural and environmental history, for a future time of enduring uncertainty.

Two ventures pioneer the messaging in space of our civilisation and are precursors to concepts broadened in the CosMuseum: The nomadic Voyager probe launched in 1977 included sound and image captures in CD prototype that Jimmy Carter, then President of America, introduced as: "This is a present from a small, distant world, a token of our sounds, our science, our images, our music, our thoughts and our feelings. We are attempting to survive our time so we may live into yours" [10]. And the Moon Arts Project, scheduled for launch in 2016. It delivers a technically advanced four chambered time capsule to the Moon establishing a permanent 'cultural heritage site', containing a discrete selection of items representative of all
Arts and Humanities with considered 'potential to last many millions if not billions of years' [11] (Figure 13). Significantly, two artworks of the author, Bottled Nymph and Noli Me Tangere are selected to be included to this project that provide an intersect between the present and the future through their use of an evolved medium, one that has origins in space science itself (Figures 14\&15). Their "otherworldly' qualities, both ethereal and cosmic, combine to empower them as objects which speak of an endless 'generative process of making meaning, making story, and understanding time' [12].

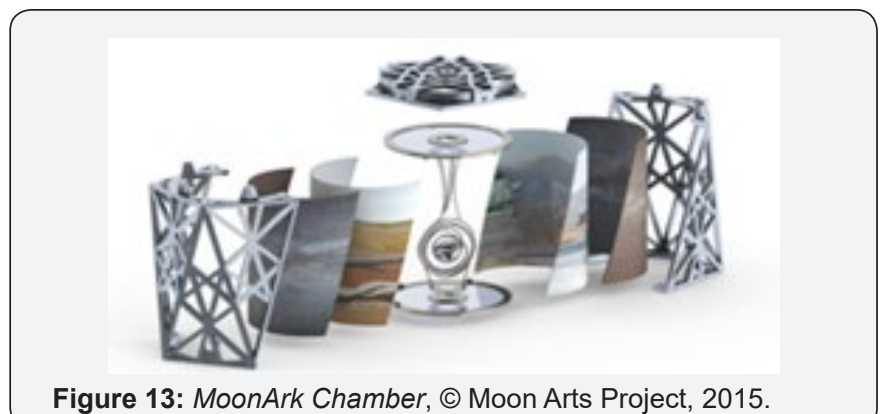

Figure 13: MoonArk Chamber, (C Moon Arts Project, 2015.

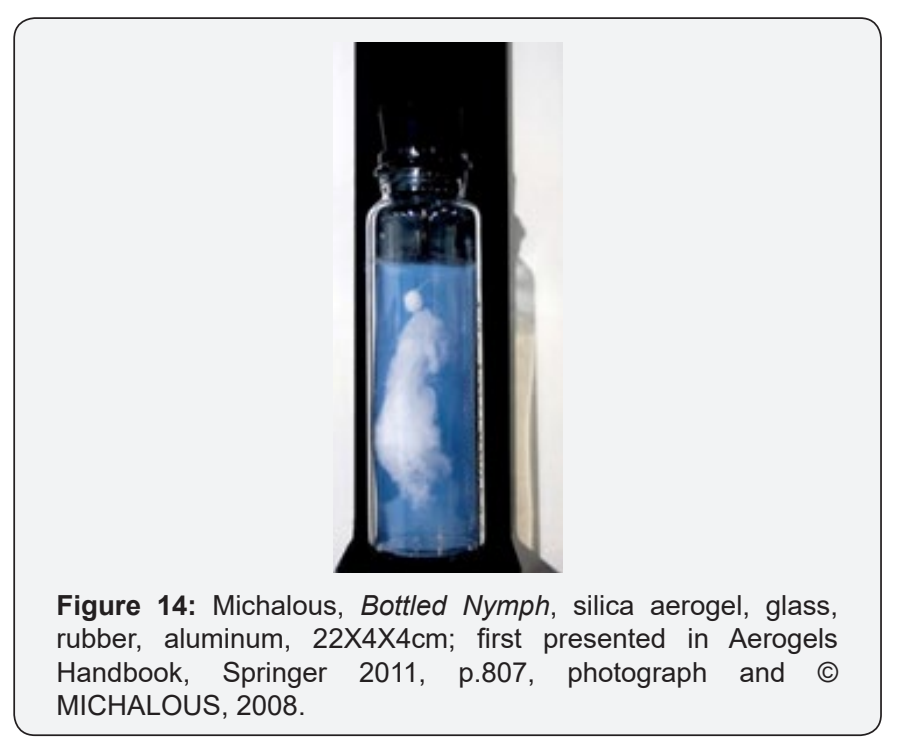

CosMuseum expands on both space incursions through development of a museographic approach that pursues an encyclopaedic rather than selective compiling of cultural data. This approach transgresses discourse between art forms, cultures, politics and geographic regions to present a pluralistic expression in virtual format of our humanity and collective history. The basis for a cultural databank as required for the collection of CosMuseum can be advanced through the development of a number of cultural collection aggregators. Known and operable examples include: 'Trove [13], Digital Public Library of America [14] and Europeana [15,16]. Each of these platforms provides digital access to collective cultural resources that cumulatively amount to almost 600 million items. A formal ontology prepared by the International Council of Museums (ICOM) through its International Committee for Documentation (CIDOC) provides a conceptual framework for integration of cultural data between disparate and diverse 
holdings [17]. Inclusive development of global content will take many decades to achieve. Consistent data standards, collaboratively applied in a sovereign approach across a global museum sector would provide an apparatus for expansion and centralised development of a globalised digital cultural heritage hub from which CosMuseum would continue to build and to draw its content for future transmission. While digital access as a process is a dissociation from the material in form and presence, the proliferation and mass of digitisation projects have already altered the cultural landscape in which museum collections are accessed across shared platforms.

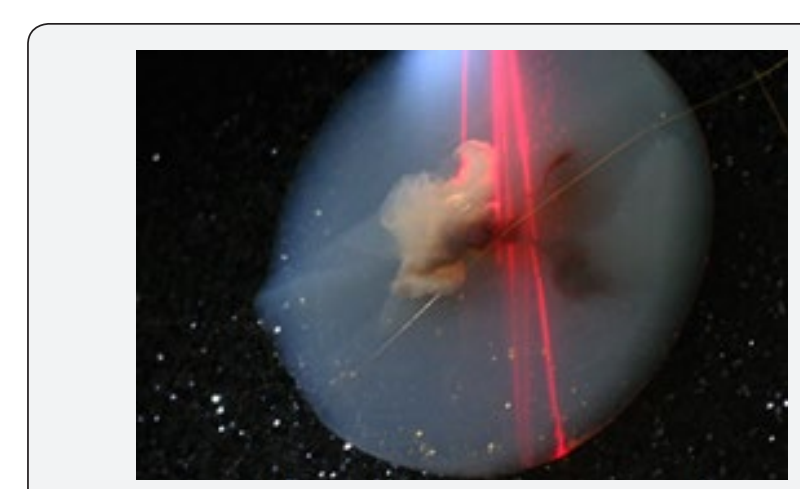

Figure 15: Michalous, Noli Me Tangere (Touch Me Not), silica aerogel, fabric, wood box, LED, laser pointer, prism, motor; interactive installation, $110 \times 40 \times 40 \mathrm{~cm}$; first presented in $3 \mathrm{rd}$ International Art\&Science Exhibition and Symposium 2012, China Science and Technology Museum, Beijing, China, photograph and ๑ MICHALOUS, 2012.

This changing access enables multiple associations and interpretations to generate. CosMuseum redefines the authentic to include its digital derivative and in doing so, enables on-going authorship of meaning and encapsulation of memory by association. Collections vulnerable to catastrophe, degeneration, decay, neglect or disinterest prevail through preservation albeit in altered or immaterial digital form/s. The concept is challenging to our traditional view of a museum as a repository filled with objects maintained in original form and functioning as true and authentic expressions of our earthbound civilisation which are illuminated in a vocabulary structured by the ideological constraints of our time. Embedded meanings associated with concepts, memories, traditions, ritual, spirituality and technical or artistic achievements are subliminal as the resemblance or presence of an object in CosMuseum bears its own significance. Material composition becomes secondary to its being in CosMuseum through the act of placement and transmission.

In juxtaposition to mineral compositions that have long preserved the evidence of our human settlement, the immaterial in virtual or newly envisaged formats becomes the evolved embalming tinctures in which the evidence of our civilization can be cradled. CosMuseum proposes that it is possible for reality to be realised at any one moment in time. The artist Grayson Perry expressed a similar sentiment in regard to uncontrived narratives during his exhibition of works at the British Museum in 2011: "That I am an artist and not a historian and this is an art exhibition does not mean it is any less real. Reality can be new as well as old, poetic as well as factual and funny as well as grim" [18]. Through aesthetic forms, in a sensory language, the CosMuseum provides a platform to experience and to remember. Development of CosMuseum is precipitated by an alliance between the museum sector and space science to innovate the project and realise technology that creates a future sustained within the universe, in which evidence of our collective humanity poses an enduring imprint. In visualizing CosMuseum examples of virtual and interactive enclosures developed by Kenderdine and team can be seen which enable access to cultural landscapes and museum collections in previously unimagined detail and resolution [19]. CosMuseum creates a virtual landscape through both its digital architecture and through its adaptive use of trans-disciplinary digital technology that holds the potential to recreate the now in the future. CosMuseum could be located either in a fixed position or as a nomadic object traversing the cosmos, subject to technical challenges in space technology and its ability to facilitate the selected global collective resources including: data transmission, data access and operability in a timeless and sustainable projection. As weight and weighted matter is a discerning feature to what could feasibly be included to a museum in the cosmos, emergence of new media explores the possibility of conversion not just in digital formats but also in weightless space materials such as aerogel adapted by Michaloudis in creation of his works. Any increase in range of payload available to space travel could include original or replicated forms to CosMuseum that would no doubt enhance humankind's physical presence within the Cosmos.

In concept, the CosMuseum holds a belief in the 'numinous' [12] experience posed through interaction with museum objects that metaphorically transport observers beyond the self as new meanings and narratives are contemplated over time and space, perhaps without possibility of being anchored to the reference to the now. Objects in the CosMuseum are as pilgrims on a journey that bear witness to our existence and evolution. In this way, there are similarities to object-centred museums purposed to make 'sense of our world by discovering and interpreting the past and present for the future' [20]. Aestheticism- as the principal agent- is designed to transmit a sensory expression that in examples of works by Michaloudis and Hance have their origins in the periphery, in prehistory, and from a region once perceived as terra nullius that paradoxically holds evidence of the longest continuous human settlement on this planet [21-23]. A fitting inclusion to a cultural package on a journey as yet not fully realized $[24,25]$.

\section{Conclusion}

The CosMuseum project is a realisation of our earthly frailty and undeterminable future. It proposes a migratory pathway through which the evidence of our civilisation can journey. Works by both artists are embedded with symbolism and 
meaning and provide example of the profundity concealed and expressed in material and immaterial forms that transgress time. The tension created through conceptualisation of cultural loss is abated through possibility of preservation and sanctity found within carriage of CosMuseum. Concepts of preservation are shown to be achievable through projects like MoonArts and other digital technologies in which museum collections are accessed and interpreted. New weightless materials such as silica aerogel allow new original works to be included in the CosMuseum as well as forming simulacra that encapsulate memories of other earthbound art works. It has been shown that these cultural cargoes embedded in a new Aestheticism of the Digital are true and authentic works-memories as well as being souvenirs from planet Earth.

\section{Acknowledgements}

The authors would like to thank the Charles Darwin Foundation for their support to this research project. Also, we thank Chris Orfescu, Anne Farren, and Carmen Ansaldo.

\section{References}

1. Hughes R (1990) Nothing if Not Critical, Harvill, HarperCollins Publishers, London.

2. Aegerter MA, Leventis N (2011), Aerogels Handbook. Springer, USA.

3. Bataille G (1929) "Informe" in Documents, no.7. Reproduced in Georges Bataille. Visions of Excess: selected, writings, 1927-1939, University of Minnesota Press, Minneapolis, Minnesota 1985, USA.

4. Baudrillard J (2005) Violence of the Virtual and Integral Reality International Journal of Baudrillard Studies 2(2): 1-16.

5. Muecke S (2016) Lecture at CDU Campus.

6. Chaloupka G (1993) Journey in Time REED William Heinemann, Australia, pp. 15.

7. Malreaux A (1967) Museum Without Walls, Secker and Warberg London, UK.

8. Michaloudis I (2004) Aer( )Sculpture: The Enigmatic Beauty of Aerogel's Non-Entity in a Pilot Art \& Science Project. Journal of NonCrystalline Solids 350: 61-66.

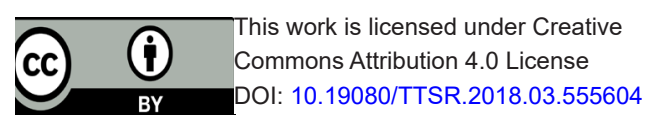

9. Muecke S, Wergin C (2014) Intensifying the tourist experience: "Survenirs" at Daly Waters Pub Tourist Studies, New York, USA 14(3): 231-245.

10. Garber M (2013) The Message Voyager 1 Carries for Alien Civilizations. The Atlantic.

11. Moon Arts Project, 2015.

12. Bedford L (2012) The Thoughtful Museum - Musing about Time and Museums. Curator-The Museum Journal 55(4): 393-400.

13. National Library of Australia and 'Trove'.

14. Digital Public Library of America (DPLA).

15. Europeana. Europeana collections.

16. Mansfield T, Winter C, Griffith C, Dockerty A, Brown T (2014) Innovation Study: Challenges and Opportunities for Australia's Galleries, Libraries, Archives and Museums. Australian Centre for Broadband Innovation, CSIRO and Smart Services, Co-operative Research Centre, Canberra, Australia.

17. International Council of Museums (ICOM) (2015) International Committee for Documentation (CIDOC) Conceptual Reference Model.

18. Francis D (2015) An Arena Where Meaning and Identity Are Debated and Contested on a Global Scale: Narrative Discourses in British Museum Exhibitions, 1972-2013. Curator - The Museum Journal 58(1): 41-60.

19. Kenderdine S (2013) Pure Land: Inhabiting the Magao Caves at Dunhuang. Curator-The Museum Journal 56(2): 199-218.

20. Museum and Art Gallery of the Northern Territory (2016) Annual Report, p. 16.

21. Baudrillard J (1988) America Trans. Chris Turner Verso, New York, USA.

22. Hooper-Greenhill E (2000). Museums and the interpretation of visual culture. London 46(3): 275-279.

23. Kenderdine S (2016) The Digital Masterpiece, presented at the World Economic Forum.

24. Koskina K (2006) Catalogue text of Ioannis MICHALOU(di)s' exhibition "11 aer( )sculptures" at the N.P. Goulandis Foundation, Museum of Cycladic Art , Athens, Greece.

25. Museum and Art Gallery of the Northern Territory (2014) Collection Policy.

\section{Your next submission with Juniper Publishers will reach you the below assets}

- Quality Editorial service

- Swift Peer Review

- Reprints availability

- E-prints Service

- Manuscript Podcast for convenient understanding

- Global attainment for your research

- Manuscript accessibility in different formats

( Pdf, E-pub, Full Text, Audio)

- Unceasing customer service

Track the below URL for one-step submission

https://juniperpublishers.com/online-submission.php 